\title{
A rare cause of small bowel obstruction
}

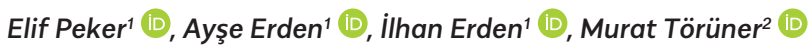 \\ 'Department of Radiology, Ankara University School of Medicine, Ankara, Turkey \\ ${ }^{2}$ Department of Gastroenterology, Ankara University School of Medicine, Ankara, Turkey
}

Cite this article as: Peker E, Erden A, Erden I, Törüner M. A rare cause of small bowel obstruction. Turk J Gastroenterol 2018; 29: 237-8.

\section{QUESTION}

A 30-year-old man was admitted to the gastroenterology department with a 3-month history of nausea, vomiting, and abdominal pain of colicky nature. The patient also complained of constipation from time to time with indefinite intervals.

Physical examination findings revealed tenderness all over the abdomen, but no palpable mass was noted. The laboratory findings were unremarkable. Mesenteric computed tomography angiography was reported to be normal at another institution. Barium follow-through examination showed small bowel dilatation.

Magnetic resonance (MR) imaging performed at our hospital revealed that the ileal segments were clustered and encapsulated within a thick oval sac in the lower abdomen (Figure 1a). Small bowel dilatation with air-fluid levels, mural enhancement, and a small amount of intraperitoneal free fluid were associated with this finding (Figure 1b). The patient underwent exploratory laparotomy with a presumptive diagnosis of bowel obstruction.

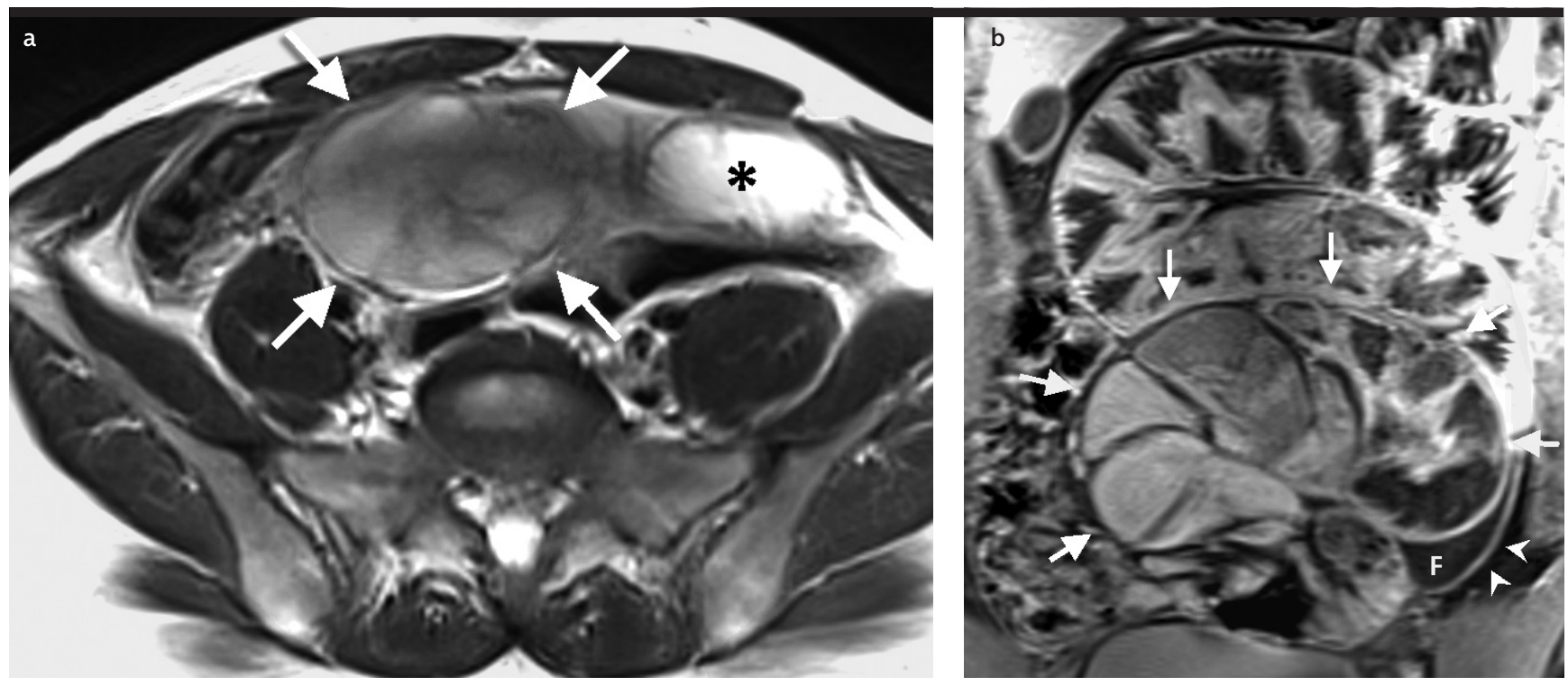

Figure 1. a, b. Axial T2-weighted MR image shows clustered ileal loops within oval sac in lower abdomen (arrows) and dilated proximal small bowel (asterisk) (a); coronal contrast-enhanced fat-suppressed, T1-weighted MR image shows dilated small bowel loops (arrows) clustered within a contrast-enhanced capsule (arrowheads) that gives an appearance of "cocoon"; a small amount of peri-intestinal fluid (F) is also seen (b)

ORCID IDs of the authors: E.P. 0000-0003-3585-6848; A.E. 0000-0002-9518-5428; I.E. 0000-0002-6274-3841; M.T. 0000-00018873-7426.

This study was presented at the 33. National Radiology Congress, TURKRAD 2012, 07-11 November 2012, Antalya, Turkey.

Address for Correspondence: Ayşe Erden E-mail: ayse.erden@medicine.ankara.edu.tr Received: July 31, 2017 Accepted: November 6, 2017

(C) Copyright 2018 by The Turkish Society of Gastroenterology · Available online at www.turkjgastroenterol.org DOI: 10.5152/tjg.2018.17478 


\section{ANSWER \\ Abdominal cocoon syndrome (sclerosing encapsulating peritonitis)}

On laparotomy, a fibrous capsule covering the small-bowel loops was found. The capsule was resected and adhesiolysis was performed. The histopathologic examination of the surgical specimen was reported as "sclerosing peritonitis." The patient's postoperative period was uneventful and he was discharged on the 8th day post operation.

Abdominal cocoon, the primary form of "sclerosing encapsulating peritonitis," is a rare condition of idiopathic etiology that results in acute or subacute intestinal obstruction due to thick, fibrotic, cocoon-like membrane, partially or totally encasing the bowel loops. Although the primary form of the disease is reported to be seen at any age and can affect both genders, adolescent girls are more commonly affected, probably as a result of retrograde menstruation. The primary form can be accompanied by embryologic abnormalities such as greater omentum hypoplasia. In the secondary form of this entity, various factors play a role in the etiopathogenesis. Continuous ambulatory peritoneal dialysis treatment is an important risk factor for sclerosing peritonitis. Beta-blockers are also supposed to contribute to the development of secondary sclerosing peritonitis (1). In addition, the disease has been described in association with prior abdominal surgery, subclinical primary viral peritonitis, intestinal transplantation, peritoneal-venous shunting, ventriculoperitoneal shunt, abdominal tuberculosis, and sarcoidosis (1-4). These conditions may predispose patients to peritoneal irritation and inflammation, which leads to peritoneal fibrinogenesis. In the patient in this study, no risk factors were found for explaining the development of sclerosing peritonitis, so the case was accepted as idiopathic, namely abdominal cocoon.

Preoperative diagnosis of this disorder is usually difficult. Diagnosis depends on clinical suspicion and imaging modalities. Barium studies may reveal a circumscribed mass of bowel loops conglomerated in one area with delayed small bowel transit time $(1,2)$. Along with appropriate clinical setting, oral and intravenous contrast enhanced computed tomography (CT) of the abdomen which shows dilated small bowel within a thick membrane, as though it were in a cocoon, is diagnostic of "sclerosing encapsulating peritonitis." The membrane surrounding the bowel causes mechanical intestinal obstruction by restricting its peristaltic activity $(2,3)$. Similar findings described for CT have been observed in MR images of the patient in this study.
Another finding which is described at surgical exploration, although not mentioned in imaging literature, was the absence or hypoplasia of omentum majus (1).

The treatment of abdominal cocoon includes surgery and nutritional support. Various surgical approaches are used in sclerosing peritonitis, such as subtotal excision of the membrane, adhesiolysis, bowel resection, and intestinal intubation (1). Since extensive bowel resection is associated with high morbidity, a simple surgical release of the entrapped bowel via removal of the fibrotic membrane without intestinal resection is the treatment of choice $(1,5)$. Some authors report that laparoscopic approach is possible for both diagnostic and therapeutic applications (5). However, laparoscopies may be technically challenging in patients with an advanced abdominal cocoon. There is a potential risk of bowel injury during laparoscopic trocar insertion and separation of the membrane from the underlying intestine in cases where thickened membrane is extensively adherent to the surrounding structures $(1,5)$.

Informed Consent: Informed consent was obtained from the patient who participated in this study.

Peer-review: Externally peer-reviewed.

Author Contributions: Concept - A.E., E.P.I.E.; Design - A.E., E.P.; Supervision - A.E., E.P., M.T., I.E.; Resource - A.E.; Materials - A.E., E.P., M.T., i.E.; Data Collection and/or Processing - A.E., E.P., I.E.; Analysis and/or Interpretation - A.E., E.P.; Literature Search - A.E., E.P.; Writing - A.E., E.P.; Critical Reviews - A.E., E.P., M.T., I.E.

Conflict of Interest: No conflict of interest was declared by the authors.

Financial Disclosure: The authors declared that this study has received no financial support.

\section{REFERENCES}

1. Tannoury JN, Abboud BN. Idiopathic sclerosing encapsulating peritonitis: abdominal cocoon. World J Gastroenterol 2012; 18: 19992004. [CrossRef]

2. Tombak MC, Apaydın D, Colak T, et al. An unusual cause of intestinal obstruction: abdominal cocoon. AJR Am J Roentgenol 2010; 194: 176-8. [CrossRef]

3. Solak A, Solak i. Abdominal cocoon syndrome: preoperative diagnostic criteria, good clinical outcome with medical treatment and review of the literature. Turk J Gastroenterol 201223: 776-9. [CrossRef] 4. Basu A, Sukumar R, Sistla SC, Jagdish S. 'Idiopathic' abdominal cocoon. Surgery 2007; 141: 277-78. [CrossRef]

5. Kropp J, Sinsakul M, Butsch J, Rodby R. Laparoscopy in the early diagnosis and management of sclerosing encapsulating peritonitis. Semin Dial 2009; 22: 304-7. [CrossRef] 